\title{
Replies to Deng, Lee, and Skow
}

\author{
Simon Prosser
}

\begin{abstract}
This paper is a contribution to a book symposium on my book Experiencing Time. I reply to comments on the book by Natalja Deng, Geoffrey Lee and Bradford Skow. Although several chapters of the book are discussed, the main focus of my reply is on chapters 2 and 6. In chapter 2 I argue that the putative mind-independent passage of time could not be experienced, and from this I develop an argument against the A-theory of time. In chapter 6 I offer one part of an explanation of why we are disposed to think that time passes, relating to the supposedly 'dynamic' quality of experienced change. Deng, Lee, and Skow's comments help me to clarify several issues, add some new thoughts, and make a new distinction that was needed, and I acknowledge, as I did in the book, that certain arguments in chapter 6 are not conclusive; but I otherwise concede very little regarding the main claims and arguments defended in the book.
\end{abstract}

\section{Introduction}

I am enormously grateful to Natalja, Geoff and Brad (hereafter Deng, Lee and Skow) for taking the time to engage with the book in such detail. Between them they raise many interesting issues; more than I can fully address here, if this piece is to be kept to a reasonable length. So I shall try to shed some further light on the issues that strike me as most central, and resist the temptation to address every single point.

First, some general comments. Experiencing Time is an attempt to both provoke and encourage further discussion of a set of issues in the philosophy of mind, and also at the intersection of philosophy of mind and metaphysics that, until the last few years, have been rather neglected. The book does not argue for a single overall thesis. But, although most of the issues that have featured in the recent philosophical literature on temporal experience are discussed in the book, there is a story running through much of the book concerning the relation between experience and the passage of time (where this is construed as the phenomenon over whose existence the A-theory and B-theory disagree). These parts of the book are the focus of the bulk of the commentators' more critical comments, so they will also be the focus of the bulk of my replies, though I shall address one or two other issues along the way.

One thing that I hope does come across from the book is that there is a set of interesting and important issues here with which we can make real progress, especially given adequate awareness of relevant empirical findings in the sciences of the mind. Much good work is being done in this field at the moment by a fastexpanding group of philosophers, and I'm certain that the next few years will bring 
much improvement in our understanding of the distinctions that must be made, the positions that can be held, and the arguments for or against them.

\section{Chapter 2: The argument against the A-theory}

The argument of chapter 2 builds upon similar arguments given in Prosser 2000, 2007, and (especially) 2013, concerning the claim that experience tells us that time passes. Since I've been going on about this for some time I'm happy to see the issue starting to receive more attention in the recent literature. I continue to believe that there is big trouble here for any version of the A-theory, and it is an issue that those interested in the metaphysics of time cannot afford to neglect (though many still do).

In very brief, the main argument of chapter 2 is this: a common reason that is given for accepting the A-theory is that experience tells us that time passes, or that the world has 'dynamic' features incompatible with the B-theory. But, according to the argument, regardless of what subjective features experience may or may not have, we cannot be veridically experiencing time passing. In order to have a veridical experience of $x$ (as opposed to, say, a non-veridical experience as of $x$, a veridical hallucination as of $x$, or an experience of something else that is mistaken for an experience of $x$ ) one must stand in a certain kind of relation to $x$, a relation that involves one's experiential state being sensitive to the occurrence of $x$. But since the putative dynamic features would be part of metaphysics, experience cannot be sensitive to them in the right sort of way; they are just not the kinds of things that experience could be telling us about. Worse still, for the A-theorist, if experience could not be telling us about the supposed dynamic features of the world, then it's not clear how we could have an adequate grasp of what those features are supposed to be; for we do not seem to have any way of understanding what the A-theorist is claiming except in relation to actual or simulated experience. So the A-theory fails to make a properly intelligible claim, and should be rejected.

I've found that this kind of argument is frequently met with bafflement. To many, it just seems so obvious that we are experiencing time passing, let alone that we know what we mean when we say that time passes, that it is a struggle to take arguments of this kind seriously. But the only way to reply to an argument is to show what is wrong with it, and to my mind no one has done so. Although a few objections have been raised, so far no two philosophers have said the same thing about where the argument is supposed to go wrong. I take that to be a good sign. Some of the objections are easy to dismiss, though those raised here by Deng, Lee and Skow are certainly more pressing than most. Before addressing them, however, I'd like to warn against one other kind of response. This is the response that accepts that dynamic features cannot be experienced, but holds that this doesn't matter because experience was never the reason for accepting the A-theory in the first place; instead, it is supposed to be a kind of default position, the common sense view that should be accepted unless there is a good reason to reject it. ${ }^{1}$ If the arguments of

${ }^{1}$ See Phillips 2016 for an example of this kind of response. 
chapter 2 are sound, however, then one should wonder how common sense could track the truth about the A-theory any better than experience can; after all, the arguments suggest that common sense would tell us the same thing, regardless of the metaphysical truth. But, in any case, there's an obvious danger that the common sense view relies on an understanding of the A-theory that is problematically linked, implicitly, to the character of experience, perhaps because in conceiving of the world as dynamic one relies on an offline simulation of experience. As I emphasise in the book, this is likely to fall foul of the worries about intelligibility (section 2.9), in which case the A-theory still fails. In light of arguments of this kind, the fact that it seems to one as though one is thinking about a certain kind of phenomenon provides very little reason, on its own, to believe that one has succeeded in doing so, let alone that reality is as one imagines it to be.

All three commentators are sympathetic to my conclusion that the putative dynamic features of the world posited by the A-theory could not be experienced, so there is little comfort here for the A-theorist. However each of them raises different doubts about whether my arguments are sufficient to establish that conclusion. In my opinion, all can be answered.

To begin with, an issue of formulation. Deng distinguishes two main claims that I make in chapter 2, which she calls claims 1 and 2. Claim 1 is that (in my own words, p. 54) 'it is impossible to experience the passage of time, and that experience does not even represent A-theoretic features (not even falsely)'. That is indeed what I claim. But she interprets 'experience' for these purposes in a narrow phenomenological sense, relating only to perception. That's not correct. The arguments of chapter 2 are intended to be extremely general. In constructing arguments of this kind one is hampered by the fact that no A-theorist has ever made it adequately clear just what aspects of experience are supposed to tell us that time passes. Now, it's not for me to tell the A-theorist what their view should be. But fortunately, for the purely negative purposes of chapter 2 , I do not have to. I do assume something that I take to be uncontroversial, that if one's experience tells one that something is the case, this is because of some aspect of 'what it is like' for one psychologically, in the broadest possible sense of 'what it is like' (though even if this assumption were denied, I doubt that it would really help the A-theorist). One can adopt a correspondingly broad sense of 'phenomenal character' in talking about this, much broader than the usual notion employed in the philosophy of perception. So, for example, even if the A-theorist's claim is that we experience time passing by virtue of comparisons that we make between current and remembered states of the world, this still corresponds to there being 'something that it is like', or a phenomenal character in the very broad sense, for the subject. Any potential way to acquire empirical knowledge counts as 'experience' in this broad sense; any way of gaining knowledge that is not purely a priori. I emphasise this because no A-theorist should think that they can avoid the objections of chapter 2 just by claiming that I am assuming too narrow a notion of 'experience'.

What Deng calls claim 2 is that the A-theory is not merely false, but unintelligible. This is what takes us from claim 1 to the B-theory. I shall say more about its interaction with claim 1 when I discuss Lee's comments, below. 
Deng worries that the broad construal of claim 1 might be in tension with one of the broader projects of the book, which is to explain why experience seems to tell us that time passes, or that we live in an A-theory world rather than a B-theory world. But there is no tension; one can deny that experience represents an A-theoretic world while still holding that there are features of experience that seem incompatible with the B-theory, or that dispose us to conceptualise the world in terms of 'motion' through time or other dynamic metaphors. I shall return to this in responding to Deng's comments on chapter 6.

I give two main arguments in chapter 2, prior to the argument about intelligibility: the detector argument and the multi-detector argument. Both are intended to show that our experiences lack a crucial kind of sensitivity to the supposed dynamic features of the world. The detector argument is a relatively blunt instrument that takes us only so far, while the multi-detector argument gets to the heart of the problem. Note that the multi-detector argument does not take the conclusion of the detector argument as a premise; it works independently.

The detector argument is a kind of debunking argument. It is intended to establish that experience would be just the same whether the A-theory or B-theory were true. In other words, experience is just as we should expect it to be, given the truth of the B-theory. This undermines the claim that the supposedly 'dynamic' character of experience conflicts with the B-theory and thus supports the A-theory. As others have noted, one might resist this conclusion by holding that the A-theory somehow provides a better explanation for the nature of experience. So I'll acknowledge here, as I do in the book, that (as Deng points out, following Skow) the detector argument does not, on its own, fully establish that experience fails to favour the A-theory. But it comes pretty close, because it is hard to see what resources the A-theorist could draw upon to argue that the A-theory gave a better explanation for experience. For example, perhaps in other contexts one might argue that one was entitled to a default presumption that things are as they appear. But the reasons for such default presumptions - such as evolutionary considerations that appeal to the normal functioning of one's perceptual apparatus - do not seem to apply in this context. Sticking with the evolutionary case, for example, both the Atheory and B-theory seem required to tell similar stories, on their own terms, about the evolutionary function of temporal experience. This follows from the fact that both theories agree on the whole sequence of physical events (more on which below), including all the events that constitute our evolutionary history. It seems likely that similar difficulties will beset any similar arguments.

In presenting the detector and multi-detector arguments I used the analogy of trying to build a physical device that detects the passage of time, in a certain sense of 'detect'. ${ }^{2}$ My intention was to make the detector argument, especially, clearer, as I suspect that there are quite a few philosophers who realise that no physical experiment can tell us which of the A- or B-theory is correct, but who have not yet noticed the implication that experience (which supervenes on physical states) can do no better. However, with hindsight, the analogy with a detector does bring a danger

${ }^{2}$ For similar arguments expressed without the detector analogies see Prosser 2013. 
of confusion; people sometimes have their own ideas about what counts as a 'detector', and can get side-tracked as a result. Skow's comments about the detector argument are a case in point. I fully acknowledge that there are some notions of 'detector' such that a physical system could be said to be detecting the passage of time, on the assumption that time does indeed pass. I acknowledge this in the book, when I say that, given the truth of the A-theory, there's a sense in which a clock could be said to be detecting (and indeed measuring) the passage of time. But what we cannot have is a physical device with a light on top such that we can use the illumination, or otherwise, of the light to tell us whether of not time passes. That's all that I need to claim about the simple detector, and Skow accepts that it is true. His objections here, it seems to me, are directed against a stronger conclusion than the one that I actually draw from this argument.

The detector argument rests on the assumption that the A- and B-theories both posit the same series of physical events. While I tried to make it clear what I meant by this, Deng's comments show that I need to be still clearer. What I say in the book is that if by 'physical event' we mean an event as described using the vocabulary of physics, then both theories agree on which physical events occur. They disagree about the metaphysical nature of the events, but not on which events occur, when the events are given a purely physical description. So here are some examples: if an A-theorist holds that two electrons collide in location $l$ at time $t$, then the B-theorist will agree. If the A-theorist holds that an electric current flows though object 0 at time $t$, causing a light to illuminate, then so does the B-theorist. And if the Atheorist holds that a certain pattern of neurons is firing at time $t$, then so does the Btheorist. These are not the kinds of things about which the theories disagree. So if, according to one theory, a light on the putative passage detector illuminates when the detector is switched on, then the other will agree. Consequently there can be no physical device such that whether or not the light illuminates will tell us whether or not time passes. And, correspondingly, if experiences supervene on physical states of the world, there can be no experience such that whether or not that experience occurs will tell us whether or not time passes. Not, at any rate, in a context in which that is what is in dispute.

In any case, the detector argument was really just a warm-up for the multidetector argument. The detector argument ought to give one a sense that experience couldn't be sensitive to the supposed dynamic phenomena in such a way as to be an experience of them. The multi-detector argument makes it clearer that this is the case. Really, the argument is quite simple. Consider the 'red' experience that you have when looking at a ripe tomato. What makes it an experience of the redness of that tomato, rather than of some other property of the tomato, or of something else? Although the details are not completely uncontroversial, there is no deep mystery here. The redness of that particular tomato caused the particular 'redness' element of the experience to occur, it did not cause any other element of the experience to occur (such as the element of experience representing the tomato's shape), and nothing else caused the 'red' element of the experience to occur (at least not in the relevant way).

The multi-detector argument challenges the A-theorist to explain how there 
could be any corresponding story about what would make it the case that some specific element of experience (and not some other element) was an experience of a dynamic feature of the world (and not an experience of something else). In the book, I argue that this challenge cannot be met. To put it simply, if experience told us that time passed (in the straightforward sense in which it tells one that the tomato is red) this would have to be because some specific element of experience was sensitive to the presence of some dynamic feature of the world; but this kind of differential sensitivity is not possible.

Skow raises several objections to this argument, but none of them work. Suppose we have an element, $\mathrm{E}$, of experience that is always present while other elements of experience come and go (Skow puts this in terms of my analogy of a detector with multiple lights; to save space, and perhaps avoid confusion, I'll translate directly to the case of experience with its many elements). Let's accept that if the A-theory were true, then it would be true that if time did not pass, E would not occur (because if time did not pass then the world would be so different from the actual world that no experience would occur at all). So there's a sense in which the occurrence of $\mathrm{E}$ would be counterfactually dependent upon time passing, and it might be suggested that this would be sufficient to regard $\mathrm{E}$ as an experience of time passing. In the book I complain that by the same reasoning every element of experience would count as an experience of time passing; and $\mathrm{E}$ would also count as an experience of everything else upon which E's occurrence would be dependent, such as the value of Planck's constant, the occurrence of the big bang, and so on.

To this, Skow replies that E could be regarded as an experience of all of those conditions; and the changeable elements of experience should not be regarded as experiences of temporal passage because they come and go according to the occurrences of other states of affairs (the presence of a ripe tomato in front of the perceiver, for example), and thus may be absent even though conditions are normal and time is passing.

For Skow's objection to work, he'd have to be right on both counts; but that cannot be the case. I'll acknowledge that someone who knows that $\mathrm{E}$ would only occur if conditions $\mathrm{C}_{1}, \mathrm{C}_{2}, \ldots \mathrm{C}_{\mathrm{n}}$ obtained could use the occurrence of $\mathrm{E}$ to infer $\mathrm{C}_{1}$, $\mathrm{C}_{2}, \ldots \mathrm{C}_{\mathrm{n}}$. So, in that limited sense, $\mathrm{E}$ could be regarded as a 'detector' for $\mathrm{C}_{1}, \mathrm{C}_{2}, \ldots$ $\mathrm{C}_{\mathrm{n}}$. Suppose, however, that someone does nothing more than connect a battery to a light bulb, sees the bulb illuminate, and says look, I have a built a detector, and it shows that time is passing, the big bang occurred, Planck's constant has such-andsuch value, etc.'. Although, as I said, given enough theory one could of course infer those conditions, in many contexts the claim would appear ridiculous - in such contexts we should rather say that this is a device that in itself detects nothing, it's just a bulb and a battery, and the most that's shown by the illumination of the bulb is that the battery is charged. More importantly, transposing to the case of experience, do we really want to say that I perceive that the big bang occurred, that Planck's constant has such-and-such a value, and so on, just because if I were equipped with suitable theoretical knowledge I could infer these things from the fact that I have experiences? I think it's clear that we should not say this. We do not take ourselves to be perceiving something just because, were it not the case, the 
experience would not have occurred. When I look at a ship sailing by on a sunny day, I do not thereby see the nuclear reactions at the centre of the sun that produced the light that illuminates the scene, even though my experience would not have occurred without them, and even though I could infer their existence given suitable theoretical assumptions. Here's one reason why: we can normally rule something out as an object of perception if it is a condition for the occurrence of all of the experiences in a given sensory modality (see p. $44 \mathrm{n}$, where I connect this point with H. H. Price's distinction between 'standing' and 'differential' conditions). I do see the ship, however, because if the ship were not there then the relevant elements of my experience would not have occurred, while the elements of experience representing the water, sky, clouds, and so on, would still be present.

What about Skow's suggestion that the changeable aspects of experience, such as a visual experience of a red tomato, would be ruled out as experiences of temporal passage just because, given the truth of the A-theory, sometimes they would not occur yet time would still be passing? Of course I agree that this lack of sensitivity is a reason why those elements of experience could not be experiences of anything dynamic. But Skow should not say this, given the other things he says. For if he were right that an experience can be of all of the conditions necessary for its occurrence, then he ought to say that each changeable element represents the conjunction of the changeable phenomenon with which it is correlated, and the passage of time (and all other such necessary conditions). The tomato experience would thus represent the conjunction of the presence of the tomato and the passage of time (and the value of Planck's constant, and so on). The conjunction would only be true when the tomato was present. But then every element of experience would be an experience of the passage of time; which is just another way of saying that just by having any kind of experience at all, once is having an experience of time passing. But the project here was to explain how just one element of experience could concern a dynamic feature of the world (where an 'element' is something less than the whole). That's what would be needed in order to defend the claim that we can experience the passage of time (or other dynamic features that entail it), rather than the somewhat implausible claim that we infer the passage of time from any experience at all, regardless of its content, even though no part of the phenomenology has any more connection with the passage of time than any other.

Speaking of 'elements' of experience, Skow's discussion of sense data shows that he has misunderstood what I had in mind with this word. In terms of the sense datum theory that he discusses, he assumes that while phenomenal characters correspond to properties of sense data, the sense data themselves are the elements of experience. If that were what I meant by an 'element' of experience then probably some of the things I say would be incorrect. But it is not what I meant. Like Skow, I reject sense-datum theories, but if one nevertheless wishes to put things in terms of sense datum theory, and if one construes sense data as items that can each have multiple phenomenological properties, then what I mean by an element of experience is a token instantiation of a phenomenological property by a sense datum. That's why I insist that there is a one-one correspondence between elements of experience and perceived features of the world. When I see a ripe tomato, there is an 
element of experience corresponding to the colour of the tomato (or perhaps many elements, corresponding to the colours of many parts of the tomato), another element corresponding to the shape of the tomato, and so on. There need be no uniquely correct individuation of elements, thus construed, but for the purposes of the multi-detector argument elements must be individuated at least as finely as phenomenological discrimination allows.

Lee's objection is more subtle. Lee accepts that experience cannot be sensitive to the passage of time, as shown by the multi-detector argument, and agrees that experience cannot tell us about metaphysical phenomena of this kind, but worries that the lack of experiential sensitivity is not sufficient to show that the passage of time cannot be experienced. He says two related things about why. Firstly, he observes (as I also do, p. 24) that space and time are perceived not directly but via the perception of spatial and temporal relations. Thus experience can tell us that the world is spatial, even though no element of experience is directly sensitive to this fact. Rather, there are elements of experiences that are sensitive to specific spatial relations, and our perception of these relations tells us that the world is spatial. Much the same is true for time and temporal relations. Similarly, Lee suggests that insofar as experience tells us that time passes, this could be because experience is sensitive to 'specific temporal facts that involve the passage of time'. He gives as an example that one might be aware of an event occurring and then getting further into the past as one attends to it in memory.

A few remarks about this. Firstly, the example is ambiguous. It could mean that as one recalls a recent event one has, via one's continuously changing memory, a continuous sense of the event 'moving' further into the past. If so, then the multidetector argument would apply straightforwardly to that sense of temporal movement; one's experience could not be differentially sensitive to the passage of a specific event through time. Perhaps one might infer something dynamic (that time passes) from something else dynamic (that this particular event is receding into the past), in much the same way that one can infer something spatial (the world is spatial) from something else spatial (this object stands in a spatial relation to that object). But this doesn't remove the problem about how experience could be differentially sensitive to something's being dynamic.

Perhaps instead Lee has something else in mind: that one's combined experience and memory have an embedded structure, such that right now they tell one that the event is, say, ten minutes into the past, but one also remembers times at which it was only five minutes into the past, and at which it was present. And Lee's question then would be why one should not be entitled to employ dynamic concepts in describing what one experiences. So, for example, one might hold that 'past', as it appears in the description just given of a structured memory, refers to the A-theoretic property of pastness, rather than the B-relation that the B-theory holds to be the semantic content of 'past' (in the book I argue that this would be a relation between a personstage and a remembered event). Lee accepts that we are not entitled to employ dynamic concepts in this way, but he thinks that my sensitivity arguments are not sufficient to show why.

Lee further illustrates his point with the example of someone who claims to know 
that light is an electromagnetic wave through direct perceptual observation. It seems that this would be mistaken, and I agree with Lee that the reason why it is mistaken cannot be that experience is not sensitive to electromagnetic waves, because it is (cf. experience is sensitive to temporal relations, and if the A-theory is correct then experience is thus sensitive to relations in dynamic time). But I do not know why Lee also thinks that the problem with the claim is not that there is no feature of experience that is sensitive to whether light is an electromagnetic wave. It seems to me that this is exactly what would be needed. It is a contingent fact that we have no such experience. The fact that light is an electromagnetic wave is, after all, an empirical discovery. We can perfectly well imagine someone, albeit very different to ourselves, whose experience would tell them this. Think of someone, for example, who had, in addition to vision, the capacity to 'feel' electric and magnetic fields. Such a person might be able to feel the fields vibrating whenever light was present, and conclude that light is an electromagnetic wave.

Let 'dynamic phenomenology' be any phenomenology that is sensitive to, and has as its content, the presence of specifically dynamic features of time (and not just time or temporal relations per se). (I don't always use 'dynamic phenomenology' in this way in the book). Either we have dynamic phenomenology or we do not. The sensitivity arguments show that we do not; whatever phenomenology we have, that we take to be sensitive to the presence of dynamic features, it cannot really be sensitive to them.

This leaves us with non-dynamic phenomenology - phenomenology that is sensitive only to B-relations or other temporal features whose metaphysical nature is in dispute. So Lee's question now is why we should not be entitled to apply dynamic, A-theoretic concepts to such experiences. But in fact this question never really arises, because we simply do not possess such concepts (despite appearances to the contrary). Concepts like 'past' are deployed via experience in a way that is causally sensitive to B-relations. Since experience is not sensitive to dynamic features such as the presence of A-properties, we simply do not have concepts with such features as their contents (this is the conclusion of the intelligibility argument, section 2.9). Perhaps it will be suggested instead that dynamic concepts acquire their contents through our understanding of their theoretic roles. This would be true for Lee's example of a electromagnetic waves, which play a role in physics. But what would be the theoretical roles of the putative dynamic features of time? They do not have theoretical roles within physics; not in the way the electromagnetic waves do. Unlike electromagnetic waves, they have no essential role in explaining how specific experiences come about, as opposed to the general claim that no experience would occur at all were time not dynamic. In any case, whatever theoretical role they are supposed to have, it does not appear that this role could make them the contents of words like 'past'; for those words, as explained above, are deployed in a way that is causally sensitive to B-relations, and thus have B-relations as their contents. This makes it impossible to claim that 'past' is a dynamic concept.

All of this can perhaps be made clearer by extending the spatial analogy a little further. I look around me, and I see two objects: object $A$ is $2 \mathrm{~m}$ to the left, and object $\mathrm{B}$ is $1 \mathrm{~m}$ to the left. I am aware that from object B's location, object A is only 
$1 \mathrm{~m}$ to the left, and from object A's location object A is 'here'. This structure of degrees of left-ness and here-ness matches the structure of pastness and presentness in the temporal example above. To keep things simple let's imagine that humans always face the same direction, so that the directions 'left' and 'right' don't change with our movements. Suppose now that there were a theory according to which space seeps from left to right. 'Seep' is only a metaphor, we are told, though no one can tell us anything much else about what it is, except that the seepage of space is entailed by the presence of properties which, according to the seepage theorist, we refer to when we use the words 'left', 'right' or 'here'. It is acknowledged that the seepage of space is not something to which experience is directly sensitive; we have no seepage phenomenology (cf. no dynamic phenomenology). But the seepage theorist nonetheless claims that we experience the seepage of space by virtue of experiencing objects with varying degrees of left-ness, right-ness or here-ness, as described above, and when we talk about left-ness and here-ness in this context we are deploying seepage concepts that refer to the properties posited by the seepage theory. The seepage theorist also holds that if this were not a world in which space seeps, there would be no conscious experience at all, because even though the laws of physics describing such a world might be isomorphic with our own, the metaphysical nature of all physical phenomena, including those upon which experience supervenes, would be utterly different.

I think it's clear that the seepage theory does not deserve to be taken seriously, and it certainly doesn't gain any support from experience. But why? I think the central reason is that the theory lacks content; it is an entirely empty speculation. We know what 'left', 'right' or 'here' mean, and they do not refer to intrinsic properties of places. The word 'left' is correctly applied just when an object stands in a certain spatial relation to the subject, and thus its content is that relation. It is because one stands in such a relation to an object that the objects looks to the left. The experience - the seepage theorist has already acknowledged - would not be sensitive to the supposed seepage-property of leftness. But the problem is not just that the seepage theorist has used words like 'left' and 'here' incorrectly. The problem is that the putative concepts employed by the seepage theory are empty. For what properties do they refer to? And, perhaps most importantly, what on earth is seepage? It is clearly not enough to hold that these properties are defined by their theoretical roles. The theoretical roles have not been specified in such a way as to individuate a unique set of properties; and, moreover, they have nevertheless been specified in such a way as to make it clear that the properties in question are not referred to by words like 'left' and 'here'. So the seepage theory is not so much false as meaningless. Moreover it wouldn't help if there were some further 'seepage' phenomenology; not if that phenomenology were not sensitive to a real phenomenon of seepage. The phenomenology might give us the illusion that there was some phenomenon called 'seepage', and that we knew what this was; but in the absence of the required sensitivity to the objective phenomenon this would be merely an illusion. The same, I have argued, is true of the A-theory, for parallel reasons.

Finally, I should briefly address two points raised by Deng concerning chapter 2 . 
Firstly, in the context of the detector argument, I discussed a view associated with Hermann Weyl, according to which 'the objective world simply is, it does not happen. Only to the gaze of my consciousness, crawling upward along the life line of my body, does a section of this world come to life as a fleeting image in space which continuously changes in time.' (1949: 116) I took this to be a version of substance dualism, in which the conscious mind 'passes' along the otherwise 'static' physical time-line. This would suggest a succession of different realities, each of which could be depicted by a diagram showing consciousness at a different position along the time line (I give a sample diagram on p. 36).

Deng interprets me as saying that the problem is that these different realities contradict one another. But, she notes, I'd already argued, against the standard McTaggart paradox, that such objections beg the question, for the A-theorist claims that the whole of reality changes as time passes, and hence no single reality contains a contradiction. This would indeed be a good reply to the complaint that the Weylian position led to contradiction, but that wasn't my objection. My objection was that each of the putative diagrams would be inaccurate, not that they would contradict one another. If the diagram shows consciousness at just one point on the time line then it depicts a world in which the person in question is conscious for just one instant, and is a zombie at all other times. But this is not correct; I, for one, was conscious ten minutes ago, and hope to still be conscious in ten minutes time. A correct diagram should therefore show my consciousness as spread out along the time line, not as occurring at just one time. But in that case it's hard to make sense of the notion of consciousness 'moving' along the time line. This undermines the Weylian view.

Secondly Deng raises a worry about my reply to an imagined quasi-Kantian position according to which the putative dynamic phenomenology, $\mathrm{P}$, supervenes on other, non-dynamic phenomenology. Just to clarify, my thought was just that nothing has been said here that would explain how the occurrence of $\mathrm{P}$ would be sensitive to the real passing of time, or other dynamic phenomena. The multidetector argument would still apply to it. This is compatible with saying (as I do) that such phenomenology might have a role in making people believe that experience is telling them time 'passes' (as they say).

\section{Chapters 3-5}

In these chapters I discuss the attitudes that we express using words like 'past' and 'future', I give an account of the way we experience durations and rates, connecting this with the rate at which time seems to pass, and I discuss the doctrine of the 'specious present' and various other issues relating to the way we experience change and duration. Chapters 4 and 5 are lengthy, and between the three chapters I put forward quite a lot of new ideas, but since there weren't too many objections from the commentators I won't say much more about them here.

I must, however, correct one misunderstanding in Lee's comments about my intentionalist account of experiences of (and thoughts about) rates and durations, in 
chapter 4. My view is that the phenomenal character of an experience of a temporal feature represents what I call a Subject-Environment Functional (SEF) relation, as does a tensed thought. This is meant to capture the role of, for example, a time interval of a given length, in the life of the perceiving subject. Thus the significance of a period of one minute in the life of a normal human might be the same as that of a period of two minutes in the life of a counterpart who is the same in all respects except for having internal processes that take place at half the rate. In the book I also tended to align this intentionalist view with a functionalist account of consciousness (though I've subsequently come to think that the same kind of intentionalism could also be combined with a form of anomalous monism). Putting these claims together, Lee says that a temporal SEF relation will be something like the relation of 'causing an internal state with such and such functional role'. Given metaphysical functionalism the representation of a temporal property then reduces to 'the temporal property that causes this kind of experience'. This, Lee points out, will ultimately make it impossible to hold a genuinely reductionist intentionalist view (where phenomenal character is reduced to representational content), and might push me toward accepting some kind of qualia view.

The view that Lee attributes to me is in fact pretty close to the non-reductive 'Fregean' view advocated by David Chalmers (2004) (albeit Chalmers does not have the temporal case as his main focus). Not surprisingly, given his anti-materialism, Chalmers has no problem with qualia (albeit he doesn't accept non-intentional qualia). But that's not what I had in mind by a SEF relation. A SEF relation can be specified without reference to the experience itself. Someone can stand in such a relation to temporal features of the world without having any particular kind of experience at all; experience serves only to tell us that we stand in such relations. Consider, for example, the relation in which one stands to a forthcoming exam, such that one has insufficient time to prepare for it. Even if one had no mental representation of the exam whatsoever, one could still stand in that relation to it (one might encounter a student who is in precisely this position). The SEF relations represented by temporal thought and experience are more general than this - they don't just concern one specific kind of action, such as not having time to prepare but they are of the same general character. As I explain in chapter 4, this allows the view to be a version of reductive intentionalism, and thus avoids any need for qualia.

\section{Chapters 6 and 7: Some partial explanations for time seeming to pass}

Overall, Experiencing Time suggests that there are many different components of our mental lives that collectively lead us to be disposed to reject the B-theory and to believe in something that we call the passage of time. Perhaps different such components dispose us toward accepting different putative A-theoretic features after all, there are many different versions of the A-theory, and together they make several quite different claims (e.g. the passage of time, the reality of tense, the open future, and so on). In chapters 6 and 7 I offer direct explanations for some of these 
components. All three commentators direct most of their more critical comments at chapter 6 , so this will be the main focus of my reply.

I'd like to emphasise that chapter 6 concerns only one part of the story about why time seems to pass - it certainly isn't the story given by the book, or even the main story. There is no main story about this; just a collection of explanations of different phenomena. (Perhaps, despite my statements to the contrary, I invited misunderstanding on this point by entitling a previous paper on the topic of chapter 6 'Why does Time Seem to Pass?' (Prosser 2012)). In the book I try to make it clear that the topic of chapter 6 is the specific claim that change is experienced as having a certain 'dynamic' quality that strikes some people as incompatible with the Btheory's 'at-at' notion of change. I suggest that change is experienced in this way because objects are experienced as enduring through changes (in the sense of being wholly present at each time, and not having temporal parts. I acknowledge that I could be running together two different notions here, though they do seem natural partners.)

The claims of chapter 6 concern phenomenology, in the narrow, perceptual sense (or at any rate as narrow a notion as is needed to capture the experience of perceived change; see chapter 5 for my own account of how narrow this is). Now, there's an emerging dispute among B-theorists over what role, if any, experience has in giving rise to A-theoretic views. I hold that the phenomenology of temporal experience does have such a role, despite the fact that it does not represent genuine dynamic features of reality (such as the passage of time). Instead, I hold that the relevant phenomenology of change represents certain contradictions. But there are other Btheorists - 'veridicalists', including Deng and Christoph Hoerl (see the works cited by Deng) - who claim that the content of experience is entirely B-theoretic, and normally veridical, and that the idea that time passes arises for some other reason.

Deng's comments have helped me to realise that in the book I failed to distinguish two different forms that veridicalism might take. One version, which I'll call moderate veridicalism, says that there is something about experience, veridical though it is, that results in our being disposed to find the A-theory plausible. The other version, which I'll call extreme veridicalism, says that we are disposed to find the A-theory plausible for reasons that have nothing to do with experience. When I suggested, in the book (p. 59), that I find veridicalism problematic because it seems to offer no explanation of why time seems to pass, and moreover no explanation of why so many of us think that experience tells us this, I had in mind extreme veridicalism. But Deng correctly points out that this is not an objection to moderate veridicalism (of which, I take it, Deng's own view is an example).

In fact Deng is right that my own view is very close to moderate veridicalism. Chapter 6 concerns the only point of disagreement; I accept that much of the story about why time seems to pass concerns our dispositions to form incorrect metaphysical beliefs as a result of a largely veridical engagement with a B-theoretic world, but I do hold that the phenomenology of perceived change contains an element that does not represent anything B-theoretic, but instead represents a kind of contradiction, which we then mistakenly describe as a dynamic feature of reality. To some extent this rests on a claim about the phenomenology with which the 
veridicalist simply disagrees (see my disagreement with Christoph Hoerl (2014), discussed on p. 185).

I could of course just be wrong about the phenomenology; this could be a case of conceptualising the phenomenology in a certain way, not required by the phenomenology itself, because of certain metaphysical views held antecedently for independent reasons. An example might be the endurance view of persistence, and in fact I shall argue below that there are indeed independent reasons for connecting the concept of endurance with the concept of temporal passage. But even if I did make that mistake, what I say in the book could still be pretty close to the right view, and just mistaken in over-interpreting the phenomenology. There is of course a rather subtle relation between what one perceives and the way in which one conceptualises what one perceives; it's not clear that the two are entirely independent. Nevertheless, I can only report that it still seems to me that there really is something in the phenomenology of any perception of change that makes it appear incompatible with the B-theorist's 'at-at' notion of change.

In support of my view in chapter 6, I argue first that if there is a seemingly 'dynamic' element of the phenomenology of change perception - an element that does not simply make the world appear as a B-theory world should appear - then the representational content of that element must be a necessary falsehood. So although the content is not A-theoretic, it is not compatible with the B-theory either. Of course merely having a necessary falsehood as content does not in itself explain why anyone would describe such a phenomenology as 'dynamic' - there will be a further story to explain this. Again, this puts me fairly close to the veridicalist position (but not quite there, just because I'm denying that change experience is fully veridical). I then suggest that the necessary falsehood in question comes about because every perceptual representation of a change involves representing the very same object (not different parts of the same object) as both $F$ and not $F$ (for some property $F$ ). I then address some obvious-seeming objections.

I initially put forward the endurance claim as a hypothesis. Then, in section 6.7, I gave a few tentative arguments in favour of the claim, though I do acknowledge (top of p. 182) that these are less than watertight. The commentators bring out the reasons why, and I acknowledge that more needs to be said before it has been made fully clear how and why experiences of change represent the changing object as enduring. The matter is not as straightforward as it might initially appear, though. I do of course hold that experience is not sensitive to whether objects endure or perdure; this is shown by arguments similar to those given in chapter 2 . But it does not follow directly that the content of experience is neutral between different theories of persistence. For the mind does have the capacity to represent identity, for independent reasons, and my thinking was that the structure of mental representations of change is such as to represent the changing object at $t_{1}$ as numerically identical with the object at $t_{2}$, where this could not be taken as equivalent to saying that the object-stage existing at $t_{1}$ is part of the same temporally extended entity as the object-stage existing at $t_{2}$ (note my remarks on the difficulties facing the paraphrase strategy that would be needed in order to defend a perdurance content, and the reasons for taking surface form as a guide to logical form in certain 
cases. I do of course realise that a failure to represent temporal parts is not equivalent to a representation of the absence of them, but there are delicate issues here about just what the correct description of the content should be.)

I don't currently have anything very substantive to add to what I say in section 6.7 of the book, though, so I won't dwell on the details of the objections to those arguments raised by the commentators, even though I do think there's a little more to the arguments than it might have appeared. Difficulties with particular arguments in favour of a position do not of course show that the position is false, and any view must be judged not only on the arguments that can be put forward directly in its favour but also on what it can explain. Instead, I'd like to say a little more by way of motivation for (if not proof of) the very general claim that mental representations of endurance, including those involved in non-perceptual cognition, have a role to play in explaining why time seems to pass. This is something that I wish I'd said more about in the book.

As I mentioned in chapter 7, there is a fair bit of empirical evidence for the claim that temporal cognition shares resources that are used for spatial cognition (p. 191). In short, in our thinking about time, we sometimes think of time as though it were space. I think that this is a further, important source of the notion that one is 'moving' through time. To see why, consider first an analogy. I feel that I am extended in space to a certain degree. My fingers and toes feel as though they are located in different places; all of the parts of my spatially extended body are felt as parts of me. There seems to be growing evidence that this sense of 'ownership' of one's body involves not only the perception of bodily parts, but also something else. There is some dispute about the details, but one currently popular view is that a sense of agency, the sense that these body parts are under one's direct control, has a crucial role.

Now, movement through space consists in being at one place at one time, and at another place at another time. An object that is, and remains, spatially extended from $\mathrm{A}$ to $\mathrm{B}$ does not move from $\mathrm{A}$ to $\mathrm{B}$ just by virtue of having a part at $\mathrm{A}$ at $t_{1}$ and a part at $\mathrm{B}$ at $t_{2}-$ not if it also has a part at $\mathrm{B}$ at $t_{1}$ and a part at $\mathrm{A}$ at $t_{2}$. So one thing that might follow is that if we think of ourselves as 'moving' through time, this would have to involve being wholly located at one time (with no parts elsewhere on the time line), and then being wholly located at another time. As metaphysics this wouldn't make much sense, of course, but the current project allows that we might well have notions that don't amount to a fully coherent worldview.

If some version of four-dimensionalism is true, as many B-theorists believe, then our bodies are extended through time as well as though space. But does it feel that way? I don't think it does; I think one has a sense of being wholly located in the present, which is why it often comes as a surprise to consider that one might in fact be a temporally extended four-dimensional object. One does have access, through memory, to earlier states of one's temporally extended body. But if we tend to think of other times as though they were other places, then by analogy with the spatial case, perhaps the mere receipt of information about one's extended body might not be sufficient for one to feel as though parts of one's body that are located in the past are currently parts of oneself. One currently has direct agency only with respect to 
those parts of one's body that are located in the present. Of course, when one thinks back to earlier times, one remembers that one did have agency with respect to the parts of oneself that were located at those times. So those parts were parts of oneself at that earlier time.

This might go some way toward explaining a sense that 'I' am wholly located in the present, but I was previously wholly located at various earlier points along the time line. It would thus provide an explanation for a sense in which it seems to me that I endure (rather than perdure) through time. And, if we are implicitly thinking of the times at which one is thus located as though they were positions in space, the only way to make sense of my having been wholly located at $A$ at $t_{1}$ and wholly located at $\mathrm{B}$ at $t_{2}$ would be that $\mathrm{I}$ moved from $\mathrm{A}$ to $\mathrm{B}$, along the time line. This would involve implicitly treating ' $\mathrm{A}$ ' and ' $\mathrm{B}$ ' as though they were locations and $t_{1}$ and $t_{2}$ as times at which one was at those locations; whereas in truth $\mathrm{A}$ and $\mathrm{B}$ just are $t_{1}$ and $t_{2}$. So, as I said, one does not thereby have a coherent metaphysics. But this might explain one source of the idea that one is 'moving' through time. It might also thus explain at least a part of what lies behind Weyl's notion of one's consciousness 'crawling' along the time line.

This line of thought needs much further development, of course. My point, for now, is that it illustrates one possible reason why thinking of oneself as enduring seems to be necessary in order to be able to think of oneself as 'moving' through time, along with a tentative explanation for why one mistakenly and incoherently does so. My broader suggestion - still tentatively - is that there may be reasons why things other than oneself may seem to 'move' along with one, and hence that change is experienced in terms of an object 'moving through' two incompatible property instantiations. As I said, though, this is no more than a broad motivation for a hypothesis related to, but not identical with, that of chapter 6. More arguments are needed.

One more reply regarding the endurance view. Skow notes that in order to fend off certain objections to the endurance view I have to deny that properties are experienced as relations to times, but he thinks that I am mistaken in doing so. $\mathrm{He}$ says 'Ask a subject: when you were looking at the second-hand, and it looked like it was here, did it look like it was here in some "atemporal" way, or did it look like this: it is here at this time (the time I'm doing the looking)? I'm confident that those who understand the question will answer the second.' But this is misleading. There are several ways to read ' $O$ is $F$ at $t$ '. One of them takes $F$ to be relational. But another takes the state of affairs at $t$ to be that $o$ is $F$. Given that we're interested in how changes are experienced it would be better to show a subject an object that changes, say from being red at $t_{1}$ to being blue at $t_{2}$, and then ask which of the following was the most appropriate description of what was experienced:

(1) Your experience told you that the state of affairs at $t_{1}$ was that the object was red, and the state of affairs at $t_{2}$ was that the object was blue.

(2) Your experience told you that the object stands in the 'red' relation to $t_{1}$ and the 'blue' relation to $t_{2}$. 
Ask it that way, and my feeling is that the first statement, which corresponds to my proposal, would be found to be the most appropriate description.

Lee and Deng both raise some issues relating to my claim that the content of seemingly dynamic experience is a necessary falsehood. I'm surprised that the claim sounds so odd, as it seems to be a fairly common claim that the A-theory holds that the reality changes between incompatible states (this comes out, for example, in Kit Fine's (2005, 2006) 'fragmentalism', and in the standard reply to McTaggart's paradox, discussed in chapter 1 of the book). It's not a new view that the passage of time involves one state of affairs being replaced by a state of affairs with which it is inconsistent. Given the A-theory, no actual contradiction arises because no single reality contains more than one of the contradicting states of affairs. But if the Btheory is true then the contradiction cannot be avoided; so it should not be very surprising if the B-theorist's story about how reality is represented, such that the Atheory seems true, involves an overall contradictory representation (and not be a contradiction concerning the state of affairs at any one time). However I'll say more about one possible source of confusion below.

Lee asks why the sense of passage should not just arise from the combination of one's memory that a certain time was present with one's knowledge that the same time is now past, and another time is present - the 'now' thus seems to have 'moved' forwards. I do discuss and endorse this possibility as part of the overall story about why time seems to pass (pp. 24, 201), but Lee is right that I should have made it more prominent. I'm puzzled by Lee's proposed version of projectivism, though. Lee suggests that our sense of a 'moving now' comes from 'illicitly projecting an awareness of genuine psychological change onto the world, where this psychological change consists in the constant updating of our tensed perspective on the world'. Here he seems to have in mind a continuous process rather than a comparison among discrete beliefs and memories, but as far as I can see my comments should largely apply to both approaches. First, a general worry about any account that takes this form: unless one is aware of the psychological change as a dynamic change, then it is hard to see why projecting it onto the world should give rise to any sense of the world undergoing a dynamic change. But no account has been offered of why the psychological change should seem like a dynamic change.

In any case, I don't understand what's supposed to be psychological here. Words like 'past' and 'present' have either an A-theory semantics or a B-theory semantics. If they had an A-theory semantics then to be aware of an event going from being present to being past would be to be aware of a change in the objective A-series position of the event. But we're assuming the B-theory at this stage, so instead these words should have a B-theory semantics. This says that words like 'past' and 'present' apply to an event (or time) if, and only if, that event (time) stands in a relation to something. The candidates for the 'something' are either the time of utterance, the utterance itself, or the speaker (or perhaps a temporal stage thereof). See chapter 3 of the book for discussion of the details. So the updating of one's tensed perspective consists in an event being represented as standing in one relation to something that exists at one time and in another relation to something that exists at another time. 
But an awareness of this content clearly does not constitute an awareness of a psychological change.

Why should an awareness of this overall content give rise to any sense of time passing? After all, the structure of past and present relations just described is much the same as the structure of 'left' and 'here' relation described above in my 'seepage' example. It's a state of affairs compatible with the B-theory, so why should it suggest anything A-theoretic to the subject? In chapter 3 I suggest one possible answer: we use monadic predicates like 'is past' and 'is present' to deal with what are really twoplace relations, and this metasemantic fact is not apparent to us in our uses of these predicates (or in the memories and experiences that lead us to judge that events are past or present). Consequently we have a tendency to think that 'past' and 'present' stand for properties of events (or times), rather than relations between events (or times) and something else. So a change from being present to being past seems to us to be a change in an objective property of reality. On this view, the experiences and/or thoughts are veridical, but we make a kind of metasemantic error in our interpretation, leading to an incorrect metaphysical view. So, given the terminology introduced above, this particular view, taken on its own, would count as an example of moderate veridicalism.

Lee suggests that if this is a source of our A-theoretic views then it is a counterexample to my claim about necessarily false contents, because the content in question would be contingent (and normally true). This is another point where my not having clearly distinguished between the different versions of veridicalism may have obscured things. If my account of the above case is correct, then it is a case in which one's experience presents the world as B-theoretic, but one makes a metasemantic error in interpreting this experience. But, although I probably didn't make this clear enough in the book, I had intended the claim that the seemingly dynamic elements of experience have necessarily false contents to apply to cases where veridicalism, even in its modest version, is false. If experience presents the world in a way that conflicts with the B-theoretic account of it, and in such a way as to seemingly lend support to an A-theoretic account, then, in those cases, I stand by the claim that the relevant element of experience has a necessarily false content. Given the assumption that all phenomenology represents something, then once veridicalism is ruled out, and given that the representation of A-theoretic features was ruled out by other arguments, the only remaining contingent candidates are contingent falsehoods compatible with the B-theory. These don't have much prima facie plausibility, and are ruled out by the argument given in the book.

\section{Bibliography}

Chalmers, D. J. 2004. The Representational Character of Experience. In B. Leiter (ed.), The Future for Philosophy. Oxford: Oxford University Press.

Fine, K. 2005. Tense and Reality. In Fine's Modality and Tense: Philosophical Papers. Oxford: Oxford University Press.

Fine, K. 2006. The Reality of Tense. Synthese, 150: 399-414. 
Phillips, I. 2016. Review of Experiencing Time by Simon Prosser, Notre Dame Philosophical Reviews, 2016.12.01.

Prosser, S. 2000. A New Problem for the A-Theory of Time. The Philosophical Quarterly, 50: 494-498.

Prosser, S. 2007. Could We Experience the Passage of Time? Ratio, 20: 75-90. Reprinted in Oaklander, L. N. (ed.), Philosophy of Time: Critical Concepts in Philosophy, volume 3. New York/London: Routledge, 2008.

Prosser, S. 2012. Why Does Time Seem to Pass? Philosophy and Phenomenological Research, 85: 92-116.

Prosser, S. 2013. Passage and Perception. Noûs, 47: 69-84.

Weyl, H. 1949. Philosophy of Mathematics and Natural Science. Based on a translation by Olaf Helmer. Princeton, NJ: Princeton University Press. Parts of an earlier version were published in German in Handbuch der Philosophie under the title 'Philosophie der Mathematik und Naturwissenschaft', R. Oldenbourg, 1927. 